\title{
A Bi-dimensional Assessment to Measure the Performance of Circular Economy: A Case Study of Tires End-of-Life Management
}

\author{
Geoffrey Lonca, Romain Muggéo, Hugue Tétreault-Imbeault, \\ Sophie Bernard and Manuele Margni
}

\begin{abstract}
Although circular initiatives emerge around the world, the process of decoupling the economic activity from resource consumption and environmental impacts is far of being achieved. The concept of circular economy embodies the opportunity to reconcile an improved resource use while reducing the environmental footprint. Appropriate assessment metrics and methodologies are needed to identify potential trade-off between these 2 sides of a single coin. In this paper, we apply the Material Circularity Indicator (MCI) and Life Cycle Assessment (LCA) to analyse tires end-of-life strategies aiming at improving the circular flow of all tire materials. Results reveal re-treading is interesting to produce trade-offs on environmental impacts while re-grooving offers a fully decoupled strategy that improves material circularity avoiding environmental burdens. Further improvements should integrate environmental assessment as well as economic factors to link micro scale to macro scale contributions to sustainable development.
\end{abstract}

\section{Introduction}

Decoupling the economic activity from any form of social and ecological degradation is gaining recognition as a universal condition to increase - or at least maintain-social welfare throughout generations (e.g. [1]). Since the idea of a sustainable development appeared, it gave birth to some concepts related to more

\footnotetext{
G. Lonca $(\bowtie) \cdot H$. Tétreault-Imbeault · M. Margni Department of Chemical Engineering, CIRAIG, École Polytechnique de Montréal, PO Box 6079 Stn. Centre-Ville, Montréal, QC H3C 3A7, Canada e-mail: geoffrey.lonca@polytml.ca

R. Muggéo

Centre de Technologies de Ladoux, M.F.P Michelin, 23 place des Carmes Déchaux, Clermont-Ferrand 63040, France
}

\section{S. Bernard}

Department of Mathematical and Industrial Engineering, École Polytechnique de Montréal, PO Box 6079 Stn. Centre-Ville, Montréal, QC H3C 3A7, Canada

E. Benetto et al. (eds.), Designing Sustainable Technologies,

Products and Policies, https://doi.org/10.1007/978-3-319-66981-6_4 
specific goals. Among them, the circular economy (CE) focuses on decoupling the economic activity from resource depletion, providing an appealing concept for companies to support the development of strategies benefitting from both saving money and resources.

CE is still a not well-defined concept that heavily builds on past ones, as suggested in the CIRAIG's white paper on circular economy released in 2015. Nonetheless, a narrow scope definition of CE jeopardizes its contribution to the bigger picture of a sustainable development. Without a clear identification of the dimensions that define a $\mathrm{CE}$, practitioners are willing to choose inadequate assessment tools that account for only a small part of the complete $\mathrm{CE}$ model. According to several definitions and metrics of CE, a company that consumes more materials and less energy is less circular than the one that consumes fewer materials and more energy [2]. This is due to an unclear definition of the boundaries between of material circularity and burden shifting, and all the more, environmental benefits are not quantitatively linked to circular strategies (i.e. circular economy loops) [3]. As the world faces a growing amount of complex products coming to their end-of-life to manage as well as recycling efficiency challenges, recycling strategies tend to consume more energy as the amount of recovered material rises $[4,5]$. Besides, technological progress make sometimes the reusing a worse environmental strategy [6], e.g. innovation on energetically efficient products leads reusing old products less efficient to increase its overall environmental impacts. Hence, the need for adequate quantifying tools for circular strategies - to enlighten decision makers towards sustainable practices - is gaining increasing attention [7].

This paper attempts to provide an approach that allows identifying trade-offs between increasing material circularity and decreasing environmental burdens to assess CE strategies through a case study on tire end-of-life management. We first identify suitable tools to assess both circularities of material flows and environmental burdens and we provide a novel approach to evaluate CE strategies (See Chapter "Sustainability performance evaluation for selecting the Best Recycling Pathway During its Design Phase"). We apply it to a case study on tire end-of-life management to identify trade-offs of CE strategies (See Chapter "A synthesis of optimization approaches for LCA-integrated industrial process modeling: application to potable water production plants"), we then discuss some limitations of our approach (See in this Chapter). Finally, concluding remarks provide insights for future works on $\mathrm{CE}$ assessment (See Chapter "Bio-based materials within the circular economy: opportunities and challenges"). 


\section{Approaches for Circular Economy Assessment}

\subsection{A Short Review on Circular Economy Assessment}

Elia et al. provide a critical review of environmental assessment tools and CE index methods [8]. They evaluate the level of alignment of the identified tools regarding five CE requirements inspired by the European Environmental Agency [9] - the report provides an outlook on resource-efficient, low-carbon economic and social development goals to achieve in 2050:

- Reducing inputs and use of natural resources;

- Reducing emission levels;

- Reducing valuable materials losses;

- Increasing the share of renewable and recyclable resources;

- Increasing the value durability of products.

Amongst the 14 environmental assessment methodologies analysed, the Life Cycle Assessment (LCA) turns out to have the best level of alignment with the $5 \mathrm{CE}$ requirements aforementioned. This is the same level of alignment as the Substance Flow Analysis (SFA), and better than the Material Flow Analysis (MFA) that does not complete requirement 3 and the Water Footprint (WF) deprived of the second requirement.

Only three out of the sixteen CE index methods published in the scientific literature in the last ten years, suits for micro-scale material circularity assessment, i.e. product or company level. Amongst the Reuse Potential Indicator (RPI) developed by Park and Chertow [10], the Circular Economy Index (CEI) by Di Maio and Rem [11] and the Material Circularity Indicator (MCI) by Ellen Mc Arthur Foundation and Granta Design [12], only the latter one accounts for the loss of material as well as product durability [8]. Even if it does not account for emission reduction (requirement 2) - but none of the micro scale CE indexes does-it appears to be the best attempt to comply with the mentioned $\mathrm{CE}$ requirements (Table 1 ).

The MCI is an index ranging between 0 and 1 . It derives from the multiplication of a Linear Flow Index (LFI) with a Utility Factor $(\mathrm{F}(\mathrm{X}))$ :

$$
\begin{aligned}
\mathrm{MCI} & =\max \left(0, \mathrm{MCI}^{*}\right) \\
\mathrm{MCI}^{*} & =1-\mathrm{LFI} \times \mathrm{F}(\mathrm{X})
\end{aligned}
$$

The LFI is a mass-based indicator that can be considered as an adapted MFA layout [13]. The LFI integrates 4 elements [see Eq. (3)]:

- The virgin feedstock fraction (v) deducted from the mass fraction of a product's feedstock from recycled sources $\left(\mathrm{F}_{\mathrm{R}}\right)$ and from reused sources $\left(\mathrm{F}_{\mathrm{U}}\right)$;

- The total waste $(\mathrm{w})$ including the waste fraction from upstream $\left(\mathrm{w}_{\mathrm{F}}\right)$ and downstream $\left(\mathrm{w}_{\mathrm{c}}\right)$ recycling processes and waste fraction directly to landfill $\left(\mathrm{w}_{0}\right)$ 
Table 1 State of the art analysis about CE measurement at micro scale retrieved from Elia et al. [8]

\begin{tabular}{l|l|l|l|l|l|l}
\hline Indicator & Author & $\begin{array}{l}\text { Reducing } \\
\text { input and } \\
\text { use of } \\
\text { natural } \\
\text { resources }\end{array}$ & $\begin{array}{l}\text { Increasing } \\
\text { share of } \\
\text { renewable and } \\
\text { recyclable } \\
\text { resources }\end{array}$ & $\begin{array}{l}\text { Reducing } \\
\text { emissions }\end{array}$ & $\begin{array}{l}\text { Reducing } \\
\text { valuable } \\
\text { material } \\
\text { losses }\end{array}$ & $\begin{array}{l}\text { Increasing } \\
\text { the value } \\
\text { durability } \\
\text { of goods }\end{array}$ \\
\hline MCI & $\begin{array}{l}\text { Ellen } \\
\text { McArthur } \\
\text { Foundation } \\
{[12]}\end{array}$ & $\mathrm{x}$ & $\mathrm{x}$ & & $\mathrm{x}$ & $\mathrm{x}$ \\
\hline CEI & $\begin{array}{l}\text { Di Maio } \\
\text { and Rem } \\
{[11]}\end{array}$ & & $\mathrm{x}$ & & & \\
\hline RPI & $\begin{array}{l}\text { Park and } \\
\text { Chertow } \\
{[10]}\end{array}$ & & $\mathrm{x}$ & & & \\
\hline
\end{tabular}

deduced from the fraction of mass of a product being collected to go to a recycling process $\left(\mathrm{C}_{\mathrm{R}}\right)$ and to reuse $\left(\mathrm{C}_{\mathrm{U}}\right)$.

- The waste fraction from upstream process $\left(\mathrm{w}_{\mathrm{F}}\right)$ derived from the efficiency of the recycling process used to produce recycled feedstock for a product $\left(\mathrm{E}_{\mathrm{F}}\right)$;

- The waste fraction from downstream process $\left(\mathrm{w}_{\mathrm{C}}\right)$ derived from the fraction of mass of a product being collected to go to a recycling process $\left(\mathrm{C}_{\mathrm{R}}\right)$ and the efficiency of the recycling process used for the portion of a product collected for recycling $\left(\mathrm{E}_{\mathrm{C}}\right)$;

$$
\begin{aligned}
& \mathrm{LFI}=\frac{\mathrm{v}+\mathrm{w}}{2+\frac{\mathrm{w}_{\mathrm{F}}-\mathrm{w}_{\mathrm{C}}}{2}} \\
& \mathrm{v}=1-\mathrm{F}_{\mathrm{R}}-\mathrm{F}_{\mathrm{U}} \\
& \mathrm{w}_{\mathrm{F}}=\mathrm{F}_{\mathrm{R}} \frac{\left(1-\mathrm{E}_{\mathrm{F}}\right)}{\mathrm{E}_{\mathrm{F}}} \\
& \mathrm{w}_{\mathrm{C}}=\mathrm{C}_{\mathrm{R}}\left(1-\mathrm{E}_{\mathrm{C}}\right) \\
& \mathrm{w}=\mathrm{w}_{0}+\frac{\mathrm{w}_{\mathrm{C}}+\mathrm{w}_{\mathrm{F}}}{2} \\
& \mathrm{w}_{0}=1-\mathrm{C}_{\mathrm{R}}-\mathrm{C}_{\mathrm{U}}
\end{aligned}
$$

$\mathrm{X}$ yields the multiplication of 2 ratios where the user is free to choose the one that better represents the product duration reality. In one case the lifetime $(\mathrm{L})$ of the assessed product is compared to the average product lifetime in the industry $\left(\mathrm{L}_{\mathrm{av}}\right)$ and in another case, the number of functional units $(\mathrm{U})$ - as per in LCA-is 
compared to the industry average $\left(\mathrm{U}_{\mathrm{av}}\right)$. It is up to the user either to choose the ratio that best fits and then to set the other at 1, or in some particular cases to use both as long as it does not produce any double counting.

$$
\begin{gathered}
\mathrm{F}(\mathrm{X})=\frac{0.9}{\mathrm{X}} \\
\mathrm{X}=\left(\frac{\mathrm{L}}{\mathrm{L}_{\mathrm{av}}}\right) \times\left(\frac{\mathrm{U}}{\mathrm{U}_{\mathrm{av}}}\right)
\end{gathered}
$$

As the MCI builds on a simplified methodology, some calculation features can be hard to identify in reality. For instance, the distinction between lifetime extension and reuse is not always clear. Furthermore, calculating the MCI of a product along one life cycle is ineffective to embrace the service it provides. E.g. in our case, one sole tire life cycle cannot be sufficient to provide a transportation service for a whole truck. It requires a repairing or a replacement to provide the same service along the whole truck's lifetime. Then, some components add up to the original product to make it last longer, resulting in a weight surplus in the product mass balance sheet. To avoid any confusion, we applied a mass-based weighting calculation that consists in dividing the product into components with any special circular feature. Thus, the $\mathrm{MCI}_{\text {total }}$ of the product accounts for the number $\left(\mathrm{n}_{\mathrm{i}}\right)$, the mass $\left(\mathrm{m}_{\mathrm{i}}\right)$ and the $\mathrm{MCI}_{\mathrm{i}}$ of every component (i) of the product [see Eq. (9)]. In our case, this equation allows incorporating the MCI value of the tire casing, the tread and the retreaded rubber band.

$$
\mathrm{MCI}_{\text {total }}=\frac{\sum_{\mathrm{i}}\left(\mathrm{n}_{\mathrm{i}} \times \mathrm{m}_{\mathrm{i}} \times \mathrm{MCI}_{\mathrm{i}}\right)}{\sum_{\mathrm{i}}\left(\mathrm{n}_{\mathrm{i}} \times \mathrm{m}_{\mathrm{i}}\right)}
$$

\subsection{An Approach Based on Trade-off Issues in Circular Economy}

Capital theory, in the field of natural resources economics, translates the objective of decoupling the economic activity from environmental degradation as an increasing substitutability between manufactured capital (capital goods) and non-renewable resources (natural capital) [14], traducing the essentialness of a resource and thus, providing a good indication of progress toward a CE. Besides, the ecological economics divides the use of the environment in 2 subsets: (1) a "use of mineral and biotic resources" that we call here "natural feedstock" and (2) a depository for waste products or residuals that we call here "environmental reservoirs" [15]. The CE should embody both environmental issues to align the capital theory of resources economics with the definition of environmental preservation from ecological economics. 


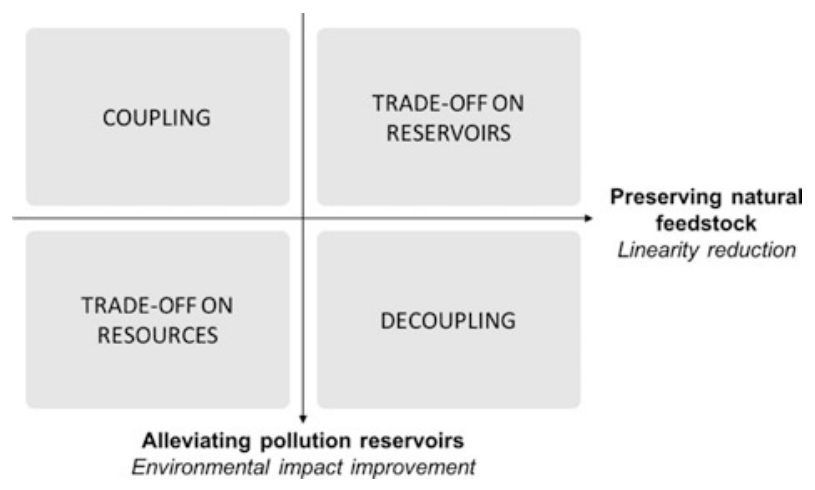

Fig. 1 A bi-dimensional approach to identify trade-off issues based on improvements on resource circularity and on environmental impacts

Let's assume a static state of the economy and disregard any consideration about the dynamic of economic activity over time. If we consider CE assessment to be bidimensional-related to the 2 subsets of use of the environment-then we identify 4 possible areas as per Fig. 1, each of them identifying a pathway departing from a baseline situation (at the origin of both axes):

- Coupling reinforcement, it reveals a pathway toward a stronger dependence on the inputs from the environment (lower circularity) ensuing more output in natural sinks (greater environmental impacts);

- Decoupling, it defines a circular strategy that is eco-efficient;

- Trade-off on resources, it means that the progress made in terms of environmental impacts require drawing on more natural resources;

- Trade-off on reservoirs, it corresponds to the particular case of burden shifting we discussed in the introduction, i.e. when saving natural resources costs more environmental externalities.

The question whether it is a relative or an absolute decoupling as Tim Jackson defined it in Prosperity without growth [16] does not interfere in our demonstration as it depends on quantitative economic features to showcase the overall level of consumption.

\section{Case Study: Tire Closed Loop Recycling}

\subsection{Data, Assumptions and Choices Modeling}

LCA has been performed in a Brazilian context in 2012 initially to guide business models of Michelin Fleet Solutions. The product analyzed is an average tire from a 
haulage truck with 32 tons' average load which usual lifetime is $600,000 \mathrm{~km}$. Data come from the Research Center of Michelin in Clermont-Ferrand (France) and the EcoInvent 2.2 database.

Hereafter is some relevant features to interpret the results. $63.5 \%$ of end-of-life tires go to energy recovery in cement clink processes and $36.5 \%$ go to material recovery (data initially retrieved from the organization responsible for collecting end-of-life tires in Brazil, Reciclanip, in 2012). For every multifunctional process of different recovery route but cast iron and extended boundaries have been considered and the co-products issued from soy esterification were considered through economic allocation. The method ReCiPe (Hierarchical perspective) Endpoint has been used to perform LCA results. For the MCI, the weighting approach for the re-treading case has been used, as per Eq. 11.

It has been assumed that tires are re-treaded 1.5 times on average after their first use. A $13.90 \mathrm{~kg}$ re-treaded rubber band (on average) replaces a tread one weighting $20.78 \mathrm{~kg}$ on average. Tire lifetime after being re-treaded is assumed to be equal to its original lifetime. However, fuel consumption increases $6.8 \%$, i.e. from $12.04 \mathrm{l} / 100$ to $12.87 \mathrm{l} / 100 \mathrm{~km}$ attributable to the re-treaded tire due to an increasing rolling resistance. In Brazil, haulage trucks consume Biofuel B5 from soy esterification. Re-grooving increases tire lifetime $30.46 \%$ on average and decreases the fuel consumption to $11.391 / 100 \mathrm{~km}(-5.4 \%)$.

\subsection{Results}

On Fig. 2, the re-grooving and re-treading scenarios are plotted relative to the baseline scenario $(0,0)$. The $\mathrm{x}$-axe represents linearity reduction which traduces

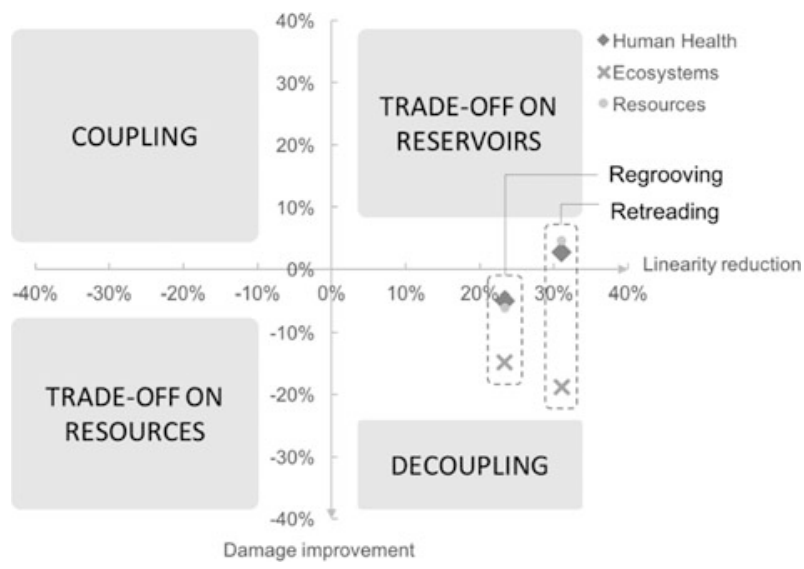

Fig. 2 Interpreting the results of 2 end-of-life tire management scenarios according to the bi-dimensional approach for circular economy assessment 
improvements on the MCI whilst y-axe represents improvements on human health, ecosystems and resources damage scores.

Results reveal that the two types of tire end-of-life management analysed tend to improve the level of circularity from the baseline scenario, as per the MCI, but it is not fully conclusive on environmental damages. Re-grooving follows on a decoupling pathway on all impact categories, whereas re-treading potentially shifts burdens on human health and resources. This is due to the increased fuel consumption required to offset the rolling resistance.

It could be tempting to conclude that re-treading improvements on circularity and ecosystem quality indicators are substantial enough to balance the small increase of damages on human health and resources, but this typical conclusion jeopardizes the preservation of natural capital itself-and consequently the contribution of circular strategies to a sustainable development. A more conservative approach then would be to conclude that only re-grooving improve natural capital preservation.

\section{Discussion}

Preceding results display areas of protection - as per $\mathrm{ReCiPe}$ - as the ultimate expression of environmental reservoirs subsets. Two important discussions stem from this observation. First, one could say that other trade-off on environmental reservoirs can occur when downscaling to mid-point categories. We considered reasonable to assume that mid-point categories can offset one another when contributing to the same damage category. Note that this works also for circularity when resource preservation refers to different subsets of stock of resources yet, this does not concern the MCI as it has no subcategories. The second logical issue is about comparing resources at damage category level and the MCI. The preceding illustration makes them appearing complementary as they derive from distinct assessment methodology. However, as both refer to natural feedstock preservation, they should follow the same trends, yet they do not.

The MCI methodology contains many limitations. For instance, system boundaries definition is narrower than in LCA, which makes the MCI ineffective to prevent from consequences of shifting resources consumption at macro scale as it refers only to one specific resource at the foreground level. Moreover, it excludes energy flows which entail neither consideration for the fuel consumption due to the increased rolling resistance nor for end-of-life energy recovery routes. Whereas, the LCA resource indicator refers to the marginal increase in costs for future extraction due to the extraction of a resource over the life cycle of the assessed product, i.e. the additional costs society has to pay as a result of an extraction [17], embodying resource depletion issues, unlike the MCI.

Finally, as the CE is meant to contribute to a sustainable development, the other sustainability dimensions are also relevant concerns. Not only social aspects are here neglected, but excluding economic factors fails to account for the dreaded 
rebound effects as per the Jevons' paradox. Economic features require special attention for future research in the field for the preceding reason, and also to assess absolute improvements on both natural resource and pollution reservoir preservation according to the approach presented in this paper.

\section{Conclusion}

Through this work, we developed a novel bi-dimensional approach to measure the performance of circular economy beyond the sole objective of resource preservation. It allows a straight forward interpretation of MCI and LCA results revealing trade-offs between improved material circularity and the risk of burden shifting over given LCA damages categories. A case study comparing 2 end-of-life tire management CE strategies revealed that re-grooving offers a fully decoupled pathway, compared to re-treading where trade-offs are identified with the increase of potential human health and resources damages. In fact, re-treading worse off impacts on human health by only $2.72 \%$, while improving circularity by $31.1 \%$ from the baseline scenario, we could question the significance of such results. Performing an uncertainty analysis would help to get fair conclusions on this issue.

To identify resource impact category as one particular environmental reservoir subset is controversial in the approach we propose. This point definitely requires further clarifications for which we recommend future research on $\mathrm{CE}$ tools to focus on the connection between micro scale and macro scale assessment. Substantial improvements should be made on the MCI, as it fails to prevent from any kind of burden shifting by excluding energy and background flows of its boundaries definition. Although the bi-dimensional analysis provides a good representation of trade-off issues, it is relative to a baseline scenario whereas absolute values are preferable, requiring economic features to be included as well.

\section{References}

1. Hotelling H, The economics of exhaustible resources, Journal of political Economy, 1931. 39 (2): p. 137-175.

2. Kampelmann S, Mesurer l'économie circulaire à l'échelle territoriale, Revue de l'OFCE, 2016 (1): p. 161-184.

3. Geyer R, et al., Common misconceptions about recycling, Journal of Industrial Ecology, 2015.

4. Bihouix P, L'Âge des low tech. Vers une civilisation techniquement soutenable, Éditions du Seuil, collection Anthropocène, 2014.

5. Bihouix P, De Guillebon B, Quel futur pour les métaux? raréfaction des métaux: un nouveau défi pour la société, 2010: EDP sciences.

6. Cooper D.R, Gutowski T.G, The Environmental Impacts of Reuse: A Review, Journal of Industrial Ecology, 2015. 
7. Su B, et al., A review of the circular economy in China: moving from rhetoric to implementation, Journal of Cleaner Production, 2013, 42: p. 215-227.

8. Elia V, Gnoni M.G, Tornese F, Measuring circular economy strategies through index methods: A critical analysis, Journal of Cleaner Production, 2017, 142: p. 2741-2751.

9. European Environmental Agency, Circular Economy in Europe-Developing the Knowledge Base (No. 2), 2016.

10. Park J.Y, Chertow M.R, Establishing and testing the "reuse potential" indicator for managing wastes as resources, Journal of environmental management, 2014, 137: p. 45-53.

11. Di Maio F, Rem P.C, A robust indicator for promoting circular economy through recycling, Journal of Environmental Protection, 2015, 6(10): p. 1095.

12. Ellen Mc Arthur Foundation and Granta Design, Circularity indicators: an approach to measuring circular economy, in Project Overview, 2015.

13. Linder M, Sarasini S, Loon P, A Metric for Quantifying Product-Level Circularity, Journal of Industrial Ecology, 2017.

14. Perman R, Natural resource and environmental economics, Pearson Education, 2003.

15. Victor P.A, Indicators of sustainable development: some lessons from capital theory, Ecological economics, 1991, 4(3): p. 191-213.

16. Jackson T, Senker P, Prosperity without growth: Economics for a finite planet, Energy \& Environment, 2011. 22(7): p. 1013-1016.

17. Goedkoop M, et al., ReCiPe 2008, A life cycle impact assessment method which comprises harmonised category indicators at the midpoint and the endpoint level, 2009. 1.

Open Access This chapter is licensed under the terms of the Creative Commons Attribution 4.0 International License (http://creativecommons.org/licenses/by/4.0/), which permits use, sharing, adaptation, distribution and reproduction in any medium or format, as long as you give appropriate credit to the original author(s) and the source, provide a link to the Creative Commons license and indicate if changes were made.

The images or other third party material in this chapter are included in the chapter's Creative Commons license, unless indicated otherwise in a credit line to the material. If material is not included in the chapter's Creative Commons license and your intended use is not permitted by statutory regulation or exceeds the permitted use, you will need to obtain permission directly from the copyright holder.

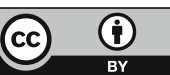

